\title{
Physiologic consequences of pneumonectomy
}

\author{
Hasan Fevzi Batirel \\ Department of Thoracic Surgery, Marmara University School of Medicine, Istanbul, Turkey \\ Correspondence to: Hasan Fevzi Batirel, MD, PhD. Marmara Universitesi Tip Fakultesi, Basıbuyuk Yolu No: 9/2, 34854 Maltepe/Istanbul, Turkey. \\ Email: hbatirel@marmara.edu.tr.
}

\begin{abstract}
Although the incidence of pneumonectomies is decreasing all around the world, it is still required in centrally located tumors and in case of destroyed lung secondary to benign diseases. In a normal person, right lung contributes $55 \%$ of lung function due to the presence of three lobes. It is well known that remaining lung tissue expands its alveolar capacity following pneumonectomy. This compensatory growth has been attributed to stimulus by shear stress which leads to pulmonary fibroblast differentiation and neoalveoalization. Pneumonectomy results in progressive deterioration of lung function (around $30 \%$ ) over the years. This leads to an increase in pulmonary artery pressure and right ventricle workload. Elderly patients with preexisting pulmonary diseases are especially at risk. On the other hand, pediatric pneumonectomies under the age of five lead to a near normal pulmonary function. There are also effects on esophagus and main bronchi due to anatomic changes in the chest cavity. However, most of the pneumonectomized patients do not experience limitations in normal life. Pneumonectomy should be avoided whenever possible if an oncologically correct operation can be performed with a lesser resection.
\end{abstract}

Keywords: Pneumonectomy; pulmonary hypertension; pulmonary function

Received: 21 April 2020; Accepted: 14 May 2020; Published: 10 April 2021.

doi: 10.21037/shc-2019-rpts-24

View this article at: http://dx.doi.org/10.21037/shc-2019-rpts-24

\section{Introduction}

Some of the pioneers of thoracic surgery, such as Harold Urschel and Jean Deslauriers have described pneumonectomy as a disease (1). This was especially true for right pneumonectomy as more lung tissue is removed and burden on the heart is much more profound.

Although the incidence of pneumonectomies is decreasing all around the world, it is still required in centrally located tumors and in case of destroyed lung secondary to benign diseases (2-4). In a recent multicenter French study on 4,498 patients who underwent pneumonectomy, in-hospital mortality rate was $7.8 \%$ (2). Mortality and morbidity rate is similar in thoracoscopic pneumonectomies (7\% and $28 \%$ respectively) and obviates the trauma and burden caused by removal of a single lung regardless of the approach (4).

In a normal person, right lung contributes $55 \%$ of lung function due to the presence of three lobes. However it is well known that remaining lung tissue expands its alveolar capacity following pneumonectomy (5). This compensatory growth has been attributed to stimulus by shear stress which leads to pulmonary fibroblast differentiation and neoalveoalization.

Other than compensatory inflation of the remaining lung, there are significant changes involving other intrathoracic organs (heart, esophagus, hemidiaphragm, chest wall). These changes become more profound with time and there are significant differences between adults and children.

This article analyzes those physiologic changes following pneumonectomy.

\section{Changes in pulmonary physiology}

\section{In adults}

Removal of a single lung leads to a significant loss of pulmonary function. Deterioration in lung function is affected by several factors. Patient's age, preoperative 


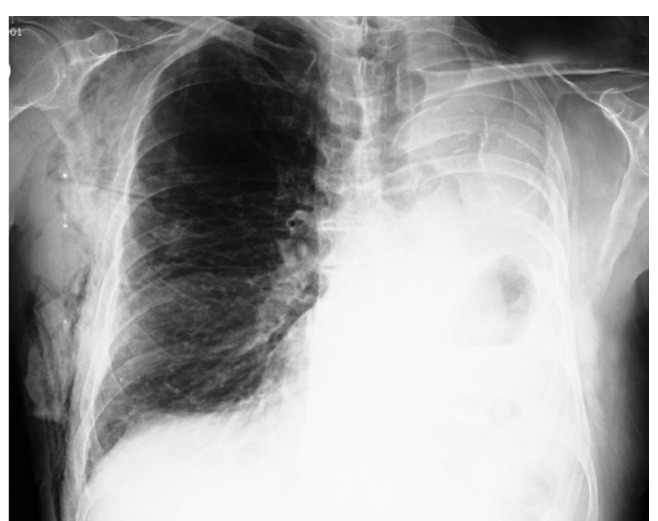

Figure 1 Compensatory hyperinflation along with emphysema and mediastinal shift in a 70-year-old male patient 10 years following left pneumonectomy for lung cancer. Shrinkage of the left pleural cavity is evident. The patient experienced a right pneumothorax and underwent a chest tube drainage and pleurodesis.

pulmonary function, time after pneumonectomy and right/ left pneumonectomy are important (Figure 1) (6).

One of the early studies analyzed effect of thoracotomy on lung function 3-6 months after surgery (7). The patients underwent different magnitudes of lung resection. Only 13 out of 106 patients underwent pneumonectomy. While thoracotomy and wedge resection did not cause a significant decrease in exercise capacity, pneumonectomy caused a $28 \%$ decrease. In this study, forced expiratory volume in onesecond $\left(\mathrm{FEV}_{1}\right)$ decreased from $2.38 \pm 0.23$ to $1.59 \pm 0.12 \mathrm{~L}$ without a significant change in oxygen saturation.

Another study was performed in Netherlands on 32 patients (surgery during 1993-1998) who were more than one year out from pneumonectomy (8). There was a decline in pulmonary function, however the results were heterogenous. Twenty-six patients were analyzed and 6 of them actually had improved pulmonary function postoperatively. $\mathrm{FEV}_{1}$ declined at a rate of $\leq 50 \mathrm{~mL} /$ year in $10,50-100 \mathrm{~mL}$ in 7 and $\geq 100 \mathrm{~mL}$ in 3 patients. Seventeen patients had analysis of exercise capacity and both workload in exercise capacity and maximal oxygen uptake $\left(\mathrm{VO}_{2} \mathrm{max}\right)$ decreased $27 \%$ and $30 \%$ respectively (8). In this study, at least $40 \%$ of the patients experienced impaired maximum exercise capacity due to ventilatory limitation following pneumonectomy.

The largest study was performed on 523 patients who underwent pneumonectomy over 20 years (1). Only 117 were alive at the time of analysis and 100 were included in the study. Decrease in $\mathrm{FEV}_{1}$ were different for the side of pneumonectomy. For right side, $\mathrm{FEV}_{1}$ decreased from $2.51 \pm 0.66$ to $1.38 \pm 0.4 \mathrm{~L}$, whereas $2.44 \pm 0.65$ to $1.53 \pm 0.37 \mathrm{~L}$ for the left side. Change were $-44 \%$ and $-34 \%$ respectively, which shows the higher impact of removal of right lung. Although changes in carbon monoxide diffusion capacity (DLCO) showed similar changes with $\mathrm{FEV}_{1}$, arterial blood gases were completely normal and six minute walking distances $(400 \pm 87 \mathrm{~m})$ were over $80 \%$. Hyperinflation was more profound after a left pneumonectomy ( $59 \%$ vs. $47 \%$ ), which would be expected as right lung is bigger than the left one.

Another study analyzed the role of pulmonary rehabilitation of post-lung resection lung function in patients with chronic obstructive pulmonary disease (COPD) (9). Eighteen out of 103 patients underwent pneumonectomy. While loss in $\mathrm{FEV}_{1}$ was much less profound in lobectomy patients who had preoperative physiotherapy (loss in $\mathrm{FEV}_{1}: 23 \%$ vs. $7 \%$, loss in vital capacity: $20 \%$ vs. $6 \%$ ), the changes in pneumonectomy patients were minimal (38\% vs. $29 \%$ for $\mathrm{FEV}_{1}, 39 \%$ vs. $33 \%$ for vital capacity).

There are conflicting reports about the role of phrenic nerve function in the ipsilateral side of pneumonectomy. From the same series of 523 patients, 88 long term survivors had magnetic resonance imaging (MRI) to assess diaphragmatic function (10). It was normal in 44, whereas paralytic or paradoxic in 44 . The authors concluded that patients with paralytic or paradoxic diaphragm movement has worse postoperative $\mathrm{FEV}_{1}$, forced vital capacity (FVC), DLCO and exercise capacity (6-minute walk test). These results were challenged in 12 patients who underwent ipsilateral phrenic nerve block following pneumonectomy which showed no difference in $\mathrm{FEV}_{1}$ pre- and post-block (11). However these were only early analysis following block and prior study results were based on long-term follow-up (10).

In these studies, decrease in $\mathrm{FEV}_{1}$ and DLCO is around $30 \%$ following pneumonectomy. Hyperinflation occurs and leads to recruitment of alveoli and better pulmonary function. Blood gas analysis shows a normal gas exchange, thus most of the patients enjoy a normal life style. Dyspnea is usually experienced upon exertion (12).

\section{In children}

Pneumonectomy is rarely indicated in children. A report of 18 children who underwent pneumonectomy for destroyed lung secondary to bronchiectasis, tuberculosis and aspergillosis showed no postoperative mortality and 
Table 1 Changes in cardiac physiology following pneumonectomy

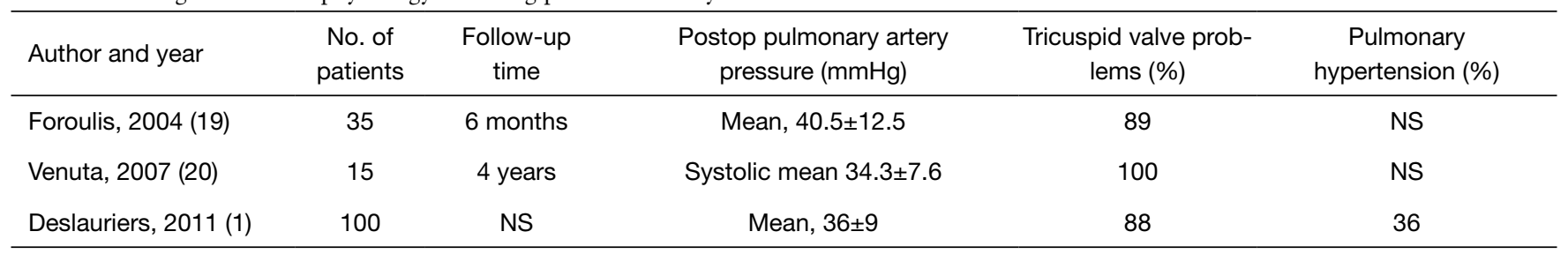

LVEF, left ventricular ejection fraction; NS, not stated.

complications in 3 patients (13). In a mean follow-up of 5 years, one patient developed scoliosis. Decrease in lung function was not as profound as adults and FVC was decreased by an average of $16.6 \%$, whereas $\mathrm{FEV}_{1}$ by an average of $18.2 \%$ as compared with preoperative values. All patients demonstrated a marked herniation of the remaining lung to the opposite side without any cardiopulmonary decompensation (13). We observed a similar case (17-yearold girl) who admitted with pneumothorax of an overly expanded right lung secondary a hypoplastic left lung (14). The presentation was similar to bilateral pneumothorax as the right lung filled the whole thoracic cavity and there was scoliosis to the left side.

In another large study from South Africa, 59 children under the age of 14 underwent pneumonectomy (15). Other than one patient with lobar emphysema, all other cases were secondary to infectious etiologies. Follow-up was not adequate and authors did not report any long term effects of pneumonectomy in children.

In an earlier study with almost 30-year follow-up, patients who were younger than 5 years of age had similar lung capacity for two lungs which is explained with compensatory growth due to hyperplasia (16). Similar to the Turkish study, in the age group 6 to 20 years, there was a slight decrease in pulmonary function, but still much better than the deterioration experienced in adult patients $(13,16)$.

Postpneumonectomy syndrome secondary to mediastinal shift occurs in $15 \%$ of the children and may lead to tracheal compression (17). It is managed by tissue expanders placed in the pneumonectomy space to prevent further shift or even aortic arch division and by-pass $(17,18)$.

\section{Changes in cardiac physiology}

Removal of a single lung leads to significant loss of pulmonary vascular bed and right side of the heart undergoes changes following pneumonectomy. The changes in pulmonary artery pressure, tricuspid valve problems and rate of pulmonary hypertension following pneumonectomy at various time periods postoperatively are shown in Table 1 $(1,19,20)$.

Pneumonectomy leads to a change of cardiac position within the chest cavity (21). The study analyzed 15 patients and a lateral shift was observed following right pneumonectomy and a rotation of the heart following left pneumonectomy. Following right pneumonectomy there was an abnormally low right ventricular (RV) end-diastolic volume with a normal left ventricular (LV) function. Left pneumonectomy was associated with normal RV volumes and abnormal LV ejection fraction. Follow-up was over 5 years and patients were tachycardic with low stroke volume indicating impaired cardiac function (21).

Right pneumonectomy was associated with more impairment of cardiac functions, especially in elderly patients with low preoperative partial arterial oxygen measurements (19). Pulmonary hypertension was found to be common in elderly patients who underwent left pneumonectomy as well (1).

However in most of the patients RV index of myocardial performance was normal and late cardiac failure was uncommon (12).

\section{Other physiologic effects}

The empty space resulting from removal of the lung is usually filled up with serous fluid (Figure 2). In case of no postoperative complication, $70 \%$ of the chest cavity is filled within a mean of 3 days (22). Median time to complete opacification of the chest with fluid was slightly over two months. It has also been reported that a spontaneous emptying of pleural fluid from the pneumonectomy cavity can occur without any evidence of a bronchopleural fistula (23). This was thought to be the results postoperative intrapleural pressure shifts.

Changes in esophageal emptying and dysphagia has been reported following right pneumonectomy (24). This 


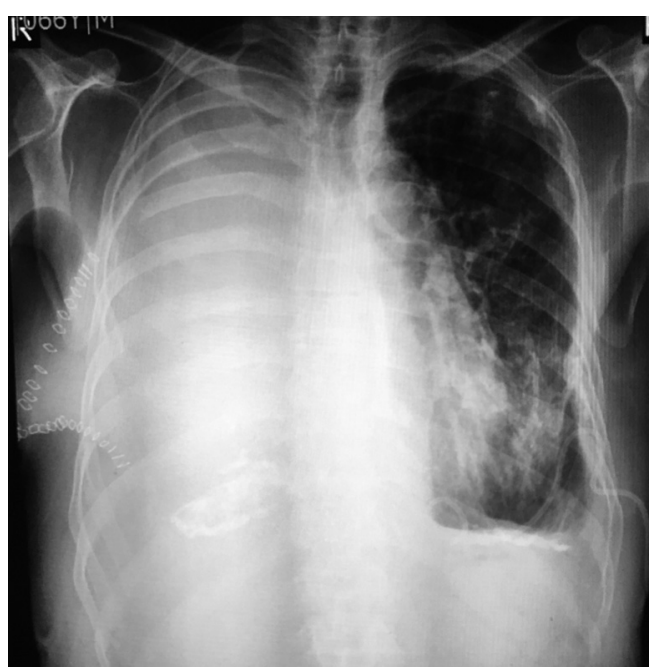

Figure 2 Early filling of the pleural space in a 65 -year-old male patient who underwent right pneumonectomy due to central cancer. The remaining lung is also severely affected from environmental asbestos exposure.

was related with mediastinal shift leading to angulation and compression of esophagus between vena cava and descending aorta.

We have also reported a gastric volvulus secondary to extreme elevation of left diaphragm 33 years following pneumonectomy (25). This leads to folding of the corpus of the stomach on itself towards the elevated left diaphragm dome. The patient was managed with laparoscopic Toupet fundoplication and gastropexy.

\section{Conclusions}

Pneumonectomy results in progressive deterioration of lung function over the years. This also leads to an increase in pulmonary artery pressure and right ventricle workload over the years. It is especially evident in elderly patients with preexisting pulmonary diseases. However, pediatric pneumonectomies under the age of five lead to a near normal pulmonary function, which proves that neoalveoalization is evident. Most of the patients do not experience limitations in normal life other than exercise or exertion. There are also effects on esophagus and main bronchi due to anatomic changes in the chest cavity.

In conclusion, it is advised to avoid pneumonectomy whenever possible due to long term physiologic burden, however it also well known that long term survival is possible after an oncologically sound operation even though it is an extended pneumonectomy.

\section{Acknowledgments}

Funding: None.

\section{Footnote}

Provenance and Peer Review: This article was commissioned by the Guest Editors (Lorenzo Spaggiari and Luca Bertolaccini) for the series "The Role of Pneumonectomy in Thoracic Surgery in The Third Millennium" published in Shanghai Chest. The article has undergone external peer review.

Conflicts of Interest: The author has completed the ICMJE uniform disclosure form (available at http://dx.doi. org/10.21037/shc-2019-rpts-24). The series "The Role of Pneumonectomy in Thoracic Surgery in The Third Millennium" was commissioned by the editorial office without any funding or sponsorship. HFB reports personal fees from Johnson and Johnson, other from Medtronic, outside the submitted work.

Ethical Statement: The author is accountable for all aspects of the work in ensuring that questions related to the accuracy or integrity of any part of the work are appropriately investigated and resolved.

Open Access Statement: This is an Open Access article distributed in accordance with the Creative Commons Attribution-NonCommercial-NoDerivs 4.0 International License (CC BY-NC-ND 4.0), which permits the noncommercial replication and distribution of the article with the strict proviso that no changes or edits are made and the original work is properly cited (including links to both the formal publication through the relevant DOI and the license). See: https://creativecommons.org/licenses/by-nc-nd/4.0/.

\section{References}

1. Deslauriers J, Ugalde P, Miro S, et al. Adjustments in cardiorespiratory function after pneumonectomy: results of the pneumonectomy project. J Thorac Cardiovasc Surg 2011;141:7-15.

2. Rivera C, Arame A, Pricopi C, et al. Pneumonectomy for benign disease: indications and postoperative outcomes, a nationwide study. Eur J Cardiothorac Surg 
2015;48:435-40.

3. Thomas PA, Berbis J, Baste JM, et al. Pneumonectomy for lung cancer: contemporary national early morbidity and mortality outcomes. J Thorac Cardiovasc Surg 2015;149:73-82.

4. Yang CJ, Yendamuri S, Mayne NR, et al. The role of thoracoscopic pneumonectomy in the management of non-small cell lung cancer: A multicenter study. J Thorac Cardiovasc Surg 2019;158:252-264.e2.

5. Haber S, Weisbord M, Mishima M, et al. Interstitial fluid flow of alveolar primary septa after pneumonectomy. J Theor Biol 2016;400:118-28.

6. Kopec SE, Irwin RS, Umali-Torres CB, et al. The postpneumonectomy state. Chest 1998;114:1158-84.

7. Nugent AM, Steele IC, Carragher AM, et al. Effect of thoracotomy and lung resection on exercise capacity in patients with lung cancer. Thorax 1999;54:334-8.

8. Smulders SA, Smeenk FW, Janssen-Heijnen ML, et al. Actual and predicted postoperative changes in lung function after pneumonectomy: a retrospective analysis. Chest 2004;125:1735-41.

9. Mujovic N, Mujovic N, Subotic D, et al. Influence of Pulmonary Rehabilitation on Lung Function Changes After the Lung Resection for Primary Lung Cancer in Patients with Chronic Obstructive Pulmonary Disease. Aging Dis 2015;6:466-77.

10. Ugalde P, Miro S, Provencher S, et al. Ipsilateral diaphragmatic motion and lung function in longterm pneumonectomy patients. Ann Thorac Surg 2008;86:1745-51.

11. Kocher GJ, Poulson JL, Blichfeldt-Eckhardt MR, et al. The importance of phrenic nerve preservation and its effect on long-term postoperative lung function after pneumonectomy. Eur J Cardiothorac Surg 2016;49:1059-62.

12. Deslauriers J, Ugalde P, Miro S, et al. Long-term physiological consequences of pneumonectomy. Semin Thorac Cardiovasc Surg 2011;23:196-202.

13. Kosar A, Orki A, Kiral H, et al. Pneumonectomy in children for destroyed lung: evaluation of 18 cases. Ann Thorac Surg 2010;89:226-31.

doi: 10.21037/shc-2019-rpts-24

Cite this article as: Batirel HF. Physiologic consequences of pneumonectomy. Shanghai Chest 2021;5:19.
14. Cardak ME, Tukel M, Demirhan R, et al. False appearance of bilateral pneumothorax in a patient with hypoplastic left lung. J Thorac Cardiovasc Surg 2012;143:e19-20.

15. Blyth DF, Buckels NJ, Sewsunker R, et al. Pneumonectomy in children. Eur J Cardiothorac Surg 2002;22:587-94.

16. Laros CD, Westermann CJ. Dilatation, compensatory growth, or both after pneumonectomy during childhood and adolescence. A thirty-year follow-up study. J Thorac Cardiovasc Surg 1987;93:570-6.

17. Choi L, LaQuaglia MP, Cordeiro PG. Prevention of postpneumonectomy syndrome in children with prophylactic tissue expander insertion. J Pediatr Surg 2012;47:1354-7.

18. Szarnicki R, Maurseth K, de Leval M, et al. Tracheal compression by the aortic arch following right pneumonectomy in infancy. Ann Thorac Surg 1978;25:231-5.

19. Foroulis CN, Kotoulas CS, Kakouros S, et al. Study on the late effect of pneumonectomy on right heart pressures using Doppler echocardiography. Eur J Cardiothorac Surg 2004;26:508-14.

20. Venuta F, Sciomer S, Andreetti C, et al. Long-term Doppler echocardiographic evaluation of the right heart after major lung resections. Eur J Cardiothorac Surg 2007;32:787-90.

21. Smulders SA, Holverda S, Vonk-Noordegraaf A, et al. Cardiac function and position more than 5 years after pneumonectomy. Ann Thorac Surg 2007;83:1986-92.

22. Munden RF, O'Sullivan PJ, Liu P, et al. Radiographic evaluation of the pleural fluid accumulation rate after pneumonectomy. Clin Imaging 2015;39:247-50.

23. Merritt RE, Reznik SI, DaSilva MC, et al. Benign emptying of the postpneumonectomy space. Ann Thorac Surg 2011;92:1076-81.

24. Yüksel M, Yildizeli B, Evman S, et al. Postpneumonectomy esophageal compression: an unusual complication. Eur J Cardiothorac Surg 2005;28:180-1.

25. Batirel HF, Uygur-Bayramicli O, Guler S, et al. Laparoscopic repair of a gastric volvulus occurring as a long-term complication of left pneumonectomy: report of a case. Surg Today 2007;37:43-5. 